\title{
FETAL OUTCOME AND VAGINAL DELIVERY RATES AMONG PRIMIGRAVIDAE WITH UNENGAGED HEAD AT ONSET OF LABOR
}

\author{
By \\ El-Sayed Ahmed El-Desouky, El-Sayed Farag and Attia Mohamed \\ Department of Obstetrics and Gynecology, Faculty of Medicine, Al-Azhar University, \\ Egypt \\ Corresponding author: El-Sayed Ahmed El-Desouky, \\ E-mail: elsayedeldesouky@yahoo.com
}

\begin{abstract}
Background: The criteria for diagnosing delivery disorders in the first and second stages of labor remain controversial. It is generally accepted that an elevated position of the fetus in primigravidas during short-term labor may indicate a threat to normal progression of labor due to fetal-pelvic disproportion or obstruction of the fetal passage by tumor or placenta.
\end{abstract}

Objective: To determine fetal outcome and vaginal delivery rates among primigravida with unengaged head at onset of labor.

Patients and Methods: This study was conducted on 250 primigravidae with unengaged fetal head presented at term in active labor during the period from January 2019 to December 2019. Any solid indication for cesarean section whether in the mother or the fetus was excluded.

These cases were given a full trial of labor and the progress of each was recorded on a partogram, The mode of delivery, the duration of labor (first and second stage), the weight of the new born and the Apgar score, were all recorded.

Also maternal morbidity and mortality were recorded. Epidural anesthesia was given to the patients on demand, and the effect of it on the mode of delivery, the duration of the first and second stage and the Apgar score were reported.

Results: Most of the patients included in the study delivered vaginally ( $82 \%)$ while only $18 \%$ delivered by cesarean section. The primigravida with unengaged fetal head at onset of labor, although at risk for C.S, most of them delivered vaginally when were given a full trial of labor and watched carefully. The length of the first and second stage of labor prolonged slightly in these patients. The need for oxytocin augmentation also increased in those patients.

The Apgar score at 1 minute and 5 minutes also decreased in the new-born of these primigravidae. There were no differences in maternal morbidity among the primigravidas presented with unengaged fetal head and those presented with engaged fetal heads. The use of epidural anesthesia did not affect the rate of C.S. although it may lengthen the duration of the first and second stage of labor. In addition, Apgar score was not affected by the use of epidural.

Conclusion: The primigravida with unengaged fetal head at onset of labor, although at risk for C.S., most of them delivered vaginally with a full trial of labor and watching carefully.

Keywords: Vaginal Delivery, Primigravida, Floating Head, Fetal Outcome. 


\section{INTRODUCTION}

Prediction of the delivery method before the onset of labor and recognizing the pregnant women who are at risk for cesarean delivery, in particular, have significant positive impact on the pregnancy outcome (El-Garhy et al., 2018).

Fetal head engagement occurs when the widest diameter of the fetal head crosses the pelvic inlet. According to the conventional theory, in nulliparous women, the fetal head engagement occurs by 38 weeks of gestation, whereas in parous women, it usually occurs at late pregnancy or during labor (Mahajan et al., 2016).

There are various factors influencing a woman's choice of mode of birth. Demographic factors and an individual's expectation of childbirth have a bearing on her decision-making process. Others are previous birth experience, potential complications arising from the mode of birth, and concerns over the health and safety of mother and baby (Loke et al., 2015).

The criteria for diagnosing labor arrest disorders in the first and second stage of labor remains controversial (Dresang and Leeman, 2012). It is generally accepted that high fetal station in primigravidae in labor near term may indicate a threat to the normal progress of labor because of feto-pelvic disproportion or obstruction of the fetal passage by tumor or the placenta.

Non engagement at the onset of active phase of labor is a predictor of the risk of cesarean section. Surgical interventions are quite high. Latent phase is prolonged and duration of first stage increased from
12-14 hours due to improper adaptation of fetal head, high station and misdirection of uterine expulsive forces (Kurshid and Sadiq, 2012). The rate of cesarean sections in such cases was $36 \%$ as compared to overall $15 \%$ incidence of cesarean sections (Mahajan et al., 2016).

The aim of this study was to determine the rate of vaginal deliveries in primigravida with floating head at onset of labor and early neonatal outcome.

\section{PATIENTS AND METHODS}

This prospective study was conducted on 250 primigravidas presented to the Obstetric Emergency Unit of Al-Azhar University Hospitals, since December 2016 till January 2018, in active labor with unengaged fetal head during labor.

After taking informed consent, full history was taken from each patient including the personal gynecological and obstetric history, medical and surgical history was also taken to exclude systemic diseases, Investigations included complete blood picture, and coagulation profile in case the patient required the use of epidural anesthesia for painless labor. Ultrasounds were done to assess the expected date of delivery.

Vaginal examination was done and cervical dilatation and effacement were determined on admission.

Labor was assessed using the partogram in every patient; fetal heart rate was monitored for each primigravida during the labor period.

In cases delivered vaginally, the duration of the first and second stage of labor were reported. The indications of cesarean section were also reported if the 
termination was by cesarean section. The Apgar sore at 1 and 5 minutes were recorded. Fetal weight was measured and recorded in grams.

\section{Statistical methods:}

Data were statistically described in terms of mean \pm SD (Standard deviation), and range, or frequencies (number of cases) and percentages when appropriate. For comparing categorical data, Chi- square test was performed. Exact test was used instead when the expected frequency is less than 5.P values less than 0.05 was considered statistically significant. All statistical calculations were done using computer programs SPSS (Statistical Package for the Social Science; SPSS Inc., Chicago, IL, USA) version 15 for Microsoft Windows.

\section{RESULTS}

Observation of the age in study group reveals the mean age is $22.5 \pm 3.38$ years. The minimum was 18 years old and the maximum was 35 years old.

The body mass index of our study ranged between 20.7-38.28 with a mean value of BMI of $27.96 \pm 3.066$ and during this study the majority of women were obese with a mean BMI of 33.2 2.38 . The gestational age ranged between a minimum of 37 weeks and a maximum of 40 weeks. The mean gestational age was $39.19 \pm 1.07$ weeks (Table 1).

Table (1): Demographic data of patients

\begin{tabular}{|c|c|}
\hline Variables & Cases $(\mathbf{n}=\mathbf{2 5 0})$ \\
\hline Age $($ years $)$ & \\
Mean \pm SD & $22.5 \pm 3.38$ \\
Range & $18-35$ \\
\hline BMI $\left(\mathbf{K g} / \mathbf{m}^{\mathbf{2}}\right)$ & $27.96 \pm 3.066$ \\
Mean \pm SD & $33.2 \pm 2.38$ \\
majority obese Range & $20.7-38.28$ \\
\hline Gestational age & \\
(weeks) & $39.19 \pm 1.07$ \\
Mean \pm SD Range & $37-40$ \\
\hline
\end{tabular}

The amniotic fluid index (AFI) of our cases ranged between $4-20 \mathrm{~cm}$ with a mean value of AFI of $9.88 \pm 1.979 \mathrm{~cm}$. The labor duration that ranged between a minimum of half an hour and a maximum of 16.5 hours. The mean duration was $6.366 \pm 2.955$ hours. The majority of women had prolonged stages of labor with a mean period of $6.552 \pm 1.88$ hours (Table 2). 
Table (2): Data during the delivery

\begin{tabular}{|c|c|}
\hline Variables & Findings \\
\hline AFI (cm) & \\
Mean \pm SD & $9.88 \pm 1.979$ \\
Range & $4-20$ \\
\hline Labor Duration (hours) & \\
Mean \pm SD & \\
Majority & $6.366 \pm 2.955$ \\
Prolonged stages & $6.552 \pm 1.88$ \\
Range & $0.5-16.5$ \\
\hline
\end{tabular}

The timing of head engagement in our study since admission ranged between 1 hour after admission, as a minimum duration, and 15 hours after admission as a maximum duration. The mean timing of head engagement was $5.51 \pm 2.76$ hours. The first stage of labor of the primigravidae in our study ranged between 0.58 hours as a minimum duration and 14.5 hours as a maximum duration. The mean duration of the first stage was $5.98 \pm 2.65$ hours. The duration of the second stage of the primigravidae in our study. It ranges between 10 minutes as a minimum duration and 150 minutes as a maximum duration. The mean duration of the second stage was $36.96 \pm 23.93 \mathrm{~min}$ (Table 3).

Table (3): Timing of engagement

\begin{tabular}{|c|c|c|c|}
\hline Time & $\begin{array}{c}\text { Time of } \\
\text { engagement } \\
\text { (Hours) }\end{array}$ & $\begin{array}{c}\mathbf{1}^{\text {st }} \text { Stage } \\
\text { Labor } \\
\text { (Hours) }\end{array}$ & $\begin{array}{c}2^{\text {nd }} \text { Stage Labor } \\
\text { (minutes) }\end{array}$ \\
\hline Mean \pm SD & $5.51 \pm 2.76$ & $5.98 \pm 2.65$ & $36.96 \pm 23.93$ \\
\hline Range & $1-15$ & $0.58-14.5$ & $10-150$ \\
\hline
\end{tabular}

The fetal heads on admission were non-engaged. The -3 station represented 16 cases $(6.4 \%)$, the -2 station represented 43.2 of cases (108 cases), while -1 station present in 126 cases $(50.4 \%)$. The majority $(57.6 \%)$ was in LOA (left occiptoanterior) (Table 4).

Table (4): Parameters of head during delivery

\begin{tabular}{|c|c|c|}
\hline Station & Number & Percentage \\
\hline 3 station & 16 & $6.4 \%$ \\
\hline 2 station & 108 & $43.2 \%$ \\
\hline 1 station & 126 & $50.4 \%$ \\
\hline
\end{tabular}

In our study, $88.4 \%(221 / 250)$ of our females have gynecoid pelvis, while Table (5): Shape of pelvis
$11.6 \%(29 / 250)$ have android pelvis (Table 5).

\begin{tabular}{|c|c|c|}
\hline Shape of pelvis & gynecoid & android \\
\hline Number (250) & $\mathbf{2 2 1}$ & 201 \\
\hline Percentage \% & $\mathbf{8 8 . 4 \%}$ & $\mathbf{8 0 . 4 \%}$ \\
\hline
\end{tabular}


In our study, $80.4 \%(201 / 250)$ of our females have adequate pelvic outlet, while
$19.6 \%(49 / 250)$ have borderline pelvic outlet (Table 6).

Table (6): Pelvic outlet

\begin{tabular}{|c|c|c|}
\hline Pelvic outlet & Adequate & Borderline \\
\hline Number (250) & 201 & 49 \\
\hline Percentage \% & $80.4 \%$ & $19.6 \%$ \\
\hline
\end{tabular}

The perineal length in females of our minimum and $5 \mathrm{~cm}$ as a maximum with a study. It ranged between $2 \mathrm{~cm}$ as a mean of $3.17 \pm 0.653 \mathrm{~cm}$ (Table 7).

Table (7): Perineal length

\begin{tabular}{|c|c|}
\hline Perineal length $(\mathbf{c m})$ & Finding \\
\hline Mean \pm SD & $3.17 \pm 0.653$ \\
Range & $2-5$ \\
\hline
\end{tabular}

Strain degree: $40.8 \%$ was excellent, $36.0 \%$ was good, $3.6 \%$ fair, and $1.6 \%$ poor (Table $8)$.

Table (8): Strain degree

\begin{tabular}{|c|c|}
\hline Strain degree & Percentage \% \\
\hline Excellent & $\mathbf{4 0 . 8 \%}$ \\
\hline Good & $\mathbf{3 6 . 0 \%}$ \\
\hline Fair & $\mathbf{3 . 6 \%}$ \\
\hline Poor & $\mathbf{1 . 6 \%}$ \\
\hline
\end{tabular}

Augmentation needed in 181 cases (72.4\%) of the pregnant women, $70 \%$ of them needed 5 units of oxytocin, while

Table (9): Augmentation

\begin{tabular}{|c|c|c|}
\hline \multirow{2}{*}{ Augmentation } & number & Percentage $\%$ \\
\hline & 181 & 72.4 \\
\hline Oxytocin (units) & \multicolumn{2}{|c|}{ Percentage \% } \\
\hline 5 & \multicolumn{2}{|c|}{$70 \%$} \\
\hline 10 & \multicolumn{2}{|c|}{$2.4 \%$} \\
\hline
\end{tabular}

We performed fundal pressure in 110 women $(44 \%)$ of the women who delivered vaginally; while we didn't perform fundal pressure in 140 cases
$2.4 \%$ needed 10 units of oxytocin for augmentation (Table

9).

Table (10): Fundal pressure

$(56 \%)$.This included $95(38 \%)$ women delivered vaginally, and 45 (18\%) women delivered by Cesarean section (Table 10). 
EL-SAYED AHMED EL-DESOUKY et al.,

\begin{tabular}{|c|c|c|}
\hline Groups & Fundal pressure & $\begin{array}{c}\text { Delivered Vaginally without } \\
\text { fundal pressure }\end{array}$ \\
\hline Number & 110 & $\begin{array}{c}140(95 \text { vaginally) } \\
(45 \mathrm{CS})\end{array}$ \\
\hline Percentage $\%$ & $44 \%$ & $56 \%(38 \%$ Vaginally) \\
$(18 \% \mathrm{CS})$
\end{tabular}

Thirty five women of our cases (14\%) received epidural analgesia while 215
(86\%) didn't receive epidural analgesia during the process of labor (Table 11).

Table (11): Epidural analgesia

\begin{tabular}{|c|c|c|}
\hline $\begin{array}{l}\text { Analgesia received } \\
\text { epidural } \\
\text { Parameters }\end{array}$ & $\begin{array}{l}\text { Women received } \\
\text { analgesia }\end{array}$ & $\begin{array}{l}\text { Women did not epidural } \\
\text { analgesia }\end{array}$ \\
\hline Number & 35 & 215 \\
\hline Percentage $\%$ & $14 \%$ & $86 \%$ \\
\hline
\end{tabular}

In our study, we needed to use the forceps successfully to deliver the baby in 8 cases $(3.2 \%)$ while $197 \quad(78.8 \%)$ delivered without the need to use forceps (Table 12).

\section{Table (12): The use of forceps}

\begin{tabular}{|c|c|c|}
\hline Farameters & $\begin{array}{c}\text { Delivered with } \\
\text { forceps }\end{array}$ & $\begin{array}{c}\text { Delivered without } \\
\text { forceps }\end{array}$ \\
\hline Number & 8 & 197 \\
\hline Percentage $\%$ & $3.2 \%$ & $78.8 \%$ \\
\hline
\end{tabular}

The mode of delivery of women in our study. 205 women of our study (82\%) delivered vaginally while 45 women

Table (13): Mode of delivery

\begin{tabular}{|c|c|c|}
\hline Mode of delivery & Vaginaly & Cesarean section \\
\hline Number & 205 & 45 \\
\hline Percentage\% & $82 \%$ & $18 \%$ \\
\hline
\end{tabular}

The number and percent of different indication of caesarean section in our study; $20 \%$ of cases underwent CS were due to arrest of progress, $68.8 \%$ for fetal distress while $11.2 \%$ of cases were due to obstructed labor (Table 14).

Table (14): Indication of cesarean section

\begin{tabular}{|c|c|}
\hline Indication of CS & Percentage \% \\
\hline Arrest of progress & $20 \%$ \\
\hline Fetal distress & $68.8 \%$ \\
\hline Obstructed labour & $11.2 \%$ \\
\hline
\end{tabular}


Episiotomy was performed in 203 $(82 \%)$ cases of vaginal delivery in our study; in 35 of them, we perform lateral episiotomy (14\%) while we performed mediolateral episiotomy in $168(86 \%)$ (Table 15).

Table (15): Episiotomy

\begin{tabular}{|c|c|c|}
\hline Episiotomy & number & Percentage\% \\
\hline Lateral episiotomy & 35 & $14 \%$ \\
\hline Mediolateral episiotomy & 168 & $86 \%$ \\
\hline Total number & $\mathbf{2 0 3}$ & $\mathbf{8 2 \%}$ \\
\hline
\end{tabular}

The number and percent of maternal complications included complete perineal tear in 8 cases $(3.2 \%)$, incomplete perineal tear in 5 cases $(2.0 \%)$ and vaginal tears in 21 cases (8\%) (Table 16).

Table (16): Complications

\begin{tabular}{|c|c|c|}
\hline Complications & Number & Percentage\% \\
\hline Complete perineal tear & 8 & $3.2 \%$ \\
\hline Incomplete perineal tear & 5 & $2 \%$ \\
\hline Vaginal tears & 21 & $8 \%$ \\
\hline
\end{tabular}

The estimated fetal weight of the newborn baby in our study ranged between $2.3-3.8 \mathrm{~kg}$ with a mean weight of $3.08 \pm 0.27 \mathrm{~kg}$, while the actual fetal

weight range between $2.0-4.3 \mathrm{~kg}$ with a mean weight of $3.15 \pm 0.36 \mathrm{~kg}$ (Table 17)..

Table (17): Estimated and actual fetal weight

\begin{tabular}{|c|c|c|}
\hline Parameters & $\begin{array}{c}\text { Estimated fetal } \\
\text { weight }(\mathrm{Kg} .)\end{array}$ & $\begin{array}{c}\text { Actual fetal weight } \\
(\mathrm{Kg} .)\end{array}$ \\
\hline Mean \pm SD & $3.08 \pm 0.27$ & $3.15 \pm 0.36$ \\
\hline Range & $2.3-3.8$ & $2.0-4.3$ \\
\hline
\end{tabular}

The Apgar score at 1 minute ranged between $0-10$ with a mean of $6.17 \pm 1.88$, and at 5 minute ranged between 1-10 with a mean value of $8.37 \pm 1.26$ (Table 18).

Table (18): Apgar score

\begin{tabular}{|c|c|c|}
\hline Apgar score & $\begin{array}{c}\text { Apgar score at 1 } \\
\text { minute }\end{array}$ & $\begin{array}{c}\text { Apgar score at 5 } \\
\text { minute }\end{array}$ \\
\hline Parameters & $6.17 \pm 1.88$ & $8.37 \pm 1.26$ \\
\hline Range \pm SD & $0-10$ & $1-10$ \\
\hline
\end{tabular}

Smooth resuscitation was found in 229 cases (91.6\%) and vigorous in 21 cases $(8.4 \%)$ (Table 19). 
Table (19): Resuscitation

\begin{tabular}{|c|c|c|}
\hline Resuscitation & smooth & vigorous \\
\hline Number & 299 & 21 \\
\hline Percentage\% & $91.6 \%$ & $8.4 \%$ \\
\hline
\end{tabular}

Twenty-one of babies $(8.4 \%)$ of our study needed to be admitted to the neonatal intensive care unit (NICU), while most of the babies $229(91.6 \%)$ passed the post- delivery period smoothly without admission (Table 20).

Table (20): Neonatal Intensive Care Unit admission (NICU)

\begin{tabular}{|c|c|c|}
\hline Narameters & $\begin{array}{c}\text { Admitted to the } \\
\text { NICU }\end{array}$ & $\begin{array}{c}\text { Without admission to } \\
\text { NICU }\end{array}$ \\
\hline Number & 21 & 299 \\
\hline Percentage\% & $8.4 \%$ & $91.6 \%$ \\
\hline
\end{tabular}

The number and percentage of primigravidae with fetal head in any station was more in the left occipto anterior than right occipto anterior. Also, the number and percentage of primigravidae with fetal head in any station was more in the right occipto posterior than left occipto posterior. The number and percentage of primigravidae with fetal head in any station were equal (Table 21).

Table (21): Correlation between the fetal head position and head station in all nonengaged cases

\begin{tabular}{|c|c|c|c|c|c|}
\hline \multirow{2}{*}{ Position } & \multirow{2}{*}{ Station } & & & & \\
\hline & & -3 & -2 & -1 & Total \\
\hline \multirow{2}{*}{$\begin{array}{c}\text { LOA (Left occipto- } \\
\text { anterior) }\end{array}$} & Count & 9 & 54 & 81 & 144 \\
\hline & $\%$ within Station & $56.25 \%$ & $46.55 \%$ & $64.29 \%$ & $57.6 \%$ \\
\hline \multirow{2}{*}{$\begin{array}{l}\text { LOP (Left occipto- } \\
\text { posterior) }\end{array}$} & Count & 0 & 0 & 3 & 3 \\
\hline & $\%$ within Station & $0.0 \%$ & $0.0 \%$ & $2.37 \%$ & $1.2 \%$ \\
\hline \multirow{2}{*}{$\begin{array}{c}\text { LOT (Left occipto- } \\
\text { transverse) }\end{array}$} & Count & 0 & 9 & 0 & 9 \\
\hline & $\%$ within Station & $0.0 \%$ & $7.67 \%$ & $0.0 \%$ & $3.6 \%$ \\
\hline \multirow{2}{*}{$\begin{array}{l}\text { ROA (Right occipto- } \\
\text { anterior) }\end{array}$} & Count & 2 & 12 & 21 & 35 \\
\hline & $\%$ within Station & $12.50 \%$ & $10.34 \%$ & $16.67 \%$ & $14 \%$ \\
\hline \multirow{2}{*}{$\begin{array}{l}\text { ROP (Right occipto- } \\
\text { posterior) }\end{array}$} & Count & 5 & 24 & 21 & 50 \\
\hline & $\%$ within Station & 31.25 & $20.68 \%$ & $16.67 \%$ & $20 \%$ \\
\hline \multirow{2}{*}{$\begin{array}{c}\text { ROT (Right } \\
\text { occiptotransverse) }\end{array}$} & Count & 0 & 9 & 0 & 9 \\
\hline & $\%$ within Station & $0 \%$ & $7.76 \%$ & $0.0 \%$ & $3.6 \%$ \\
\hline \multicolumn{2}{|c|}{ Significance } & \multicolumn{4}{|c|}{$\mathrm{P}<0.01$} \\
\hline
\end{tabular}

The more the pelvis was towards the android shape the more was the head high in station, and the more was towards gynecoid, the more was the head low in station. There was a good positive correlation between the gynecoid pelvis and the head station and engagement. The more the pelvic outlet was adequate the more the head low in station, and the more the pelvic outlet was border line the more the head was high in station. There was a good positive correlation between adequate pelvic outlet and the head station and engagement (Table 22). 
FETAL OUTCOME AND VAGINAL DELIVERY RATES AMONG...

Table (22): Correlation between (the shape of pelvis - pelvic outlet) and head station in non-engaged cases

\begin{tabular}{|c|c|c|c|c|c|}
\hline Shape of the pelvis & Station & -3 & -2 & -1 & Total \\
\hline Gynecoid & Count & 14 & 90 & 117 & 221 \\
\hline & $\%$ within station & $87.5 \%$ & $83.33 \%$ & $92.24 \%$ & $88.4 \%$ \\
\hline Android & Count & 2 & 18 & 9 & 29 \\
\hline \multicolumn{2}{|c|}{ Significance within station } & $12.5 \%$ & $16.67 \%$ & $7.76 \%$ & $11.6 \%$ \\
\hline \multicolumn{2}{|c|}{} & $\mathrm{P}>0.05$ & & & \\
\hline Pelvic outlet & station & -3 & -2 & -1 & Total \\
\hline \multirow{2}{*}{ Adequate } & Count & 11 & 85 & 111 & 207 \\
\cline { 2 - 6 } & $\%$ within station & $68.75 \%$ & $78.7 \%$ & $88.1 \%$ & $82.8 \%$ \\
\hline \multirow{2}{*}{ Borderline } & Count & 5 & 23 & 15 & 43 \\
\cline { 2 - 6 } & $\%$ within station & $31.25 \%$ & $21.3 \%$ & $11.9 \%$ & $17.8 \%$ \\
\hline \multirow{2}{*}{ Significance } & & $\mathrm{P}>0.05$ & & & \\
\hline
\end{tabular}

There was a good positive correlation between the station and the incidence of cesarean section. The more the head was high in station the more was the incidence of cesarean section. Also, there was a negative correlation between the high station and the incidence of vaginal delivery, so the more the head was high in station the less was the chance of deliver vaginally (Table 23).

Table (23): Correlation between the mode of delivery and head station in nonengaged cases of our study

\begin{tabular}{|c|c|c|c|c|c|}
\hline \multicolumn{2}{|c|}{ Mode of delivery } & Station & & & \\
\cline { 3 - 6 } & Count & -3 & -2 & -1 & Total \\
\hline \multirow{2}{*}{ C.S } & $\%$ within station & $18.75 \%$ & $21.3 \%$ & $16.67 \%$ & $19 \%$ \\
\cline { 2 - 6 } & Count & 13 & 85 & 105 & 203 \\
\hline \multirow{2}{*}{ Vaginal } & $\%$ within station & $81.25 \%$ & $78.7 \%$ & $83.33 \%$ & $81 \%$ \\
\hline \multicolumn{2}{|c|}{ Significance } & P $>0.05$ & & & \\
\cline { 2 - 6 }
\end{tabular}

The more the pelvic outlet was adequate the less the maternal complications which was a negative correlation between adequacy of pelvic outlet and maternal complications. Also, there was a positive correlation between the high station and the incidence of maternal complication so, the more the head was high in station the more the incidence of maternal complications.

Table (24): Correlation between the pelvic outlet and maternal complications in non-engaged cases of our study

\begin{tabular}{|c|c|c|c|c|}
\hline \multirow{2}{*}{ Pelvic outlet } & & \multicolumn{2}{|c|}{ Maternal complications } & \\
\cline { 3 - 5 } & & Yes & No & Total \\
\hline \multirow{2}{*}{ Adequate } & Count & 52 & 155 & 207 \\
\cline { 2 - 5 } & $\%$ within station & $66.66 \%$ & $90.12 \%$ & $82.8 \%$ \\
\hline \multirow{2}{*}{ Borderline } & Count & 26 & 17 & 43 \\
\cline { 2 - 5 } & $\%$ within station & $33.34 \%$ & $9.88 \%$ & $17.2 \%$ \\
\hline Significance & & \multicolumn{4}{|l}{$\mathrm{P}<0.001$ significant } & \\
\hline
\end{tabular}




\section{DISCUSSION}

Labor is the onset of regular uterine contractions followed by progressive cervical dilatation, effacement and descent of presenting part. Fetal head is said to be engaged when its widest diameter has fit into the pelvic inlet (Mahajan et al., 2016).

Agrawal and his Colleagues (2015) reported that the gestational age of their cases ranged between 37-40 week which was in agreement with Current study.

Mahendra and Prameela (2014) included primigravidae with gestational age 3842 gestational age, which was contradicting with Current results "more gestational age than Current study".

Also, Madaan and his Colleagues (2015) included primigravidae with gestational age ranged between 36 to 38 weeks at the time of enrollment which is also in contradict with Current study "gestational age less than Current study".

The amniotic fluid index (AFI) of current cases ranged between $4-20 \mathrm{~cm}$ with a mean value of $9.881 .979 \mathrm{~cm}$. Madaan and his Colleagues (2015) found that the mean AFI was maximum, between 34-36 weeks, i.e. $13.1 \mathrm{~cm}$ after which it gradually decreased to $9.08 \mathrm{~cm}$ beyond 40 weeks. Mean AFI of patients with $<40$ weeks of gestation gradually decreased from $12.2-8.0 \mathrm{~cm}$ after 42 weeks implies significant relationship between post-term pregnancy and AFI which was in agreement with Current results. Morris and his Colleagues (2014) recommend in their study any intervention in the presence of borderline AFI.

The majority of our cases showed prolonged stages of labor 6.5521 .88 hours (ranged between 0.5- 16.5 hours). The head took 1-15 hours to be engaged from the onset of admission with a mean of 5.512 .76 hours.

In contrary to current study, Mahajan and Colleagues (2016) showed that the non-engagement of the head most commonly due to deflexed head in $28 \%$ women, cephalopelvic disproportion (CPD) in $13.34 \%$, loop of the cord around the neck in $6 \%$, placenta previa in $5.33 \%$ whereas no cause could be identified in $40 \%$.

The stages of labor in current study prolonged either the first stage which ranged 0.58 - 14.5 hours with a mean of 5.98 hours, or the second stage which ranged between 10-150 minutes with a mean of $36.96 \mathrm{~min}$.

Mahendra and Prameela (2014) showed that the average duration of $1 \mathrm{st}$ stage of labor was 13 hour and $13 \mathrm{~min}$ ranged between 19-10.5 hour, and increased with increase with the level of the head (station -3, -2, -1). Also, average duration of second stage was $37 \mathrm{~min}$.

Also, El-Nassery and Coworkers (2013) showed that the length of the first stage ranged from 1.5 hour to 14.5 hours (mean 5.98 hour), while the duration of the second stage ranged from 30 minutes to 150 minutes with a mean of 46.69 minutes and this agree with Current results.

Sudhir and Mishra (2016) showed that the length of $1^{\text {st }}$ stage of labor ranged from 7.5-10.75 hrs and the duration of $2^{\text {nd }}$ stage of labor ranged from 50-110 min which was in agreement with current results.

Most of cases of our study showed a head about to be engaged (station -1) 
$(50.4 \%)$ and a minority were highly nonengaged (station -3$)(6.4 \%)$.

Khurshid and Sadiq (2012) found that the causes of high head station was deflexed head, cephalopelvic disproportion, premature rupture of membranes, placenta praevia, loops of cord around the neck, hydramnios, hydrocephalus and prematurity.

In current study, the most common presenting part of the vertex was LOA (left occipto-anterior)- (57.6\%), followed by ROP (right occipto-posterior) -(20\%), while the least presenting part was LOP (left occipto-posterior)- (1.2\%), with no specific correlation between a specific type of presentation and head station.

Simkin (2010) also found that the occipito-anterior position is ideal for birth, and the position is usually 'Left Occiput Anterior (LOA). Occasionally, the baby may be Right Occiput Anterior (ROA). The perineal length in females of the current study ranged between $2-5 \mathrm{~cm}$ with a mean of $3.170 .653 \mathrm{~cm}$. Lan and his Colleagues, (2017) found that the mean perineal body length among these primigravid women averaged $3.7 \mathrm{~cm}$, with a range of 2.3-5.0 $\mathrm{cm}$. Among those women, the rate of third and fourth-degree lacerations was $3.9 \%$. They also found that both the duration of second stage of labor and perineal body length were found to have significant while it was independently associated with third- and fourth-degree lacerations, which was in agreement of current results.

In Current study, the use of oxytocin for augmenting the uterine contraction was used in $72.4 \%$ of our cases in $70 \%$ of them we use 5 IU of oxytocin while in $2.4 \%$ of cases we used 10 IU of Oxytocin.
In Mahajan and Colleagues study (2016) found that $90 \%$ of their cases needed augmentation by administered oxytocin. Also, El-Nassery and Coworkers, (2013) agree with these results and found in their study that oxytocin needed to augment delivery in $72 \%$ of their study.

In the current study we use fundal pressure in $44 \%$ of cases to help in vaginal delivery. In addition, we need to use the forceps to deliver $3.2 \%$ of cases which was used successfully. Sudhir and Mishra, (2016), use forsceps in $11.66 \%$ of cases of their stud to deliver their cases which disagree with our study.

In current study, we administer epidural analgesia in (14\%) to relief pain during the process of labor. El-Nassery and Coworkers (2013) agree with these results and found in their study that epidural analgesia needed to be administered in $14 \%$ of their cases to relief pains during delivery (El-Nassery et al., 2013).

In the current study, $82 \%$ of cases delivered spontaneously through vagina, while $18 \%$ of cases we need to shift to CS mostly due to fetal distress $(68.8 \%)$ and arrested progress of labor $(20 \%)$ of obstructed labor $(11.2 \%)$. There was a positive correlation between the head station and the incidence of cesarean section, the more the head was high in station the more was the incidence of caesarean section.

In the study of Mahendra and Prameela (2014), 53\% had normal vaginal delivery, $20 \%$ instrumental delivery and $26.9 \%$ delivered by CS. There was need to resort to forceps/ventose or LSCS in 
nearly half of the cases and this disagree with Current study.

The current study the indications for CS were arrest of progress in $20 \%$, fetal distress $68.8 \%$ and obstructed labor in $11.2 \%$. In agreement with the current study, Mahajan and Colleagues (2016) found that the cause of CS were arrest progress, fetal distress, and deep transverse arrest but disagree with Current study that they need CS in $36 \%$ of their cases.

In addition to this, El Nassery and Coworkers (2013) found that vaginal delivery was achieved in $79.3 \%$ of patients whereas cesarean section was performed to $20.7 \%$. Indications of cesarean section were arrest progress, fetal distress and obstructed labor which agree with the current results.

Shaikh and his Colleagues (2014) found that vaginal delivery occurred in $59 \%$ and CS in $41 \%$ and the most common cause of unengaged head was deflexed head in $28 \%$ women, cephalopelvic disproportion (CPD) in $18 \%$, loop of the cord around the neck in $4 \%$, placenta previa (anterior) in $4 \%$, and hydrocephalus in $1 \%$ while no cause could be identified in $45 \%$ and these results disagreed with the current results.

Sudhir and Mishra (2016) found that $48.3 \%$ of their cases delivered vaginally, $35 \%$ delivered by CS, $11.66 \%$ delivered by the aid of forsceps and $5 \%$ of cases delivered with the aid of ventous This was in contrary with the current results study.

In the current, study spontaneous vaginal delivery occurred in $82 \%$ of cases and we needed to do episiotomy in $(81.2 \%)$ most of them were mediolateral episiotomy (in $86 \%$ of cases we use it) and lateral episiotomy in little cases (14\%).

El-Nassery and Coworkers (2013) showed that $78.9 \%$ of their cases needed to have episiotomy during vaginal deliver which agreed with the current results.

In the current study, we encountered complications in $13.6 \%$ of cases most of them were vaginal tears $8.4 \%$, complete perineal tear in $3.2 \%$, and partial perineal tear in $2 \%$ of cases. In this way, there was a positive correlation between the rate of maternal complications and the adequacy of pelvic outlet regarding maternal outcome.

Mahajan and their Colleagues (2016) reported a rate of complications more than the current study $22 \%$ and postpartum hemorrhage (PPH) occurred 10.67\%, perineal tear in $3.33 \%$, wound infection in $5.33 \%$, cervical tear in $1.33 \%$ and prolonged hospital stay in $1.33 \%$ cases.

Sheikh and his Colleagues (2014) found that maternal outcome after delivery showed postpartum hemorrhage $(\mathrm{PPH})$ occurred in $10 \%$ of women, perineal tear in $2 \%$ and wound infection in $7 \%$,which disagreed with the current results. The mean estimated fetal weight in the current study was within the normal ranged for age "ranged 2.3-3.8 kg with a mean weight of $3.080 .27 \mathrm{~kg}$ ". This agreed with Mehandra and Prameela, (2014), who found that the average birth weight was $2.37 \mathrm{~kg}$ ranged from $2.5-4.5 \mathrm{~kg}$.

The APGAR score at 1 minute, which ranged between $0-10$ with a mean of 6.17 1.88 and that APGAR score at 5 minute that ranged between 1-10 with a mean value of 8.371 .26 which was within the 
normal range. Mahajan and Colleagues (2016) showed that Apgar score at 5 minute was between 3-10 in in cases of the study this was in agreement of Current study.

Also, El-Nassery and Coworkers (2013) found that APGAR score at 1 minute and at 5 minutes ranged between $1-10$, and the need for admission to NICU was needed in $5.3 \%$ of their cases which agreed the with current results.

Sheikh and his Colleagues (2014) found that fetal outcome as regards Apgar score at 5 minute was 7- 10 in 75\%, 4-6 in $20 \%, 3$ and below in 5\% neonates and $10 \%$ of neonates required admission to NICU which was in agree with current results .Sudhir and Mishra (2016) showed in their study that Apgar score at 5 minute was below 3-10 in in cases of the study this was in agreement of current study. The resuscitative course of most of the babies $(91.6 \%)$ passed smooth while $8.4 \%$ of babies the course passes vigorous and needed to be admitted to the NICU. In agreement with the current study, Mahajan and colleagues, (2016), showed in their study that $9.33 \%$ of their cases (babies) needed to be admitted to the NICU.

\section{CONCLUSION}

Not all primigravidas presented with engaged fetal head. The primigravida with unengaged fetal head at onset of labor, although at risk for C.S. most of them will deliver vaginally they are given a full trial of labor and watched carefully. The length of the first and second stage of labor might be prolonged slightly in these patients. The need for oxytocin augmentation is also increased in these patients. The Apgar score at 1 minute and
5 minutes are also decreased in the newborn of these primigravidas. There were no differences in maternal morbidity among the primigravidas presented with unengaged fetal head and those presented with engaged fetal heads. The use of epidural anesthesia doesn't affect the rate of C.S. although it may lengthen the duration of the first and second stage of labor and the Apgar score is not affected by the use of epidural.

\section{RECOMMENDATION}

Primigravidas, healthy females with unengaged fetal head of a full-term singleton gestation without maternal or fetal condition, if they give the chance with augmentation they deliver normally in most cases. The study should be done on a large scale of cases in different countries and races.

\section{REFERENCES}

1. Agrawal S., Agrawal V. and Yadav S. (2015): Comparative study of amniotic fluid index in normal and high risk pregnancy complicated by PIH. Indian J Obst Gynecol Res; 2(4): 242-245.

2. Dresang T.L. and Leeman L. (2012): Cesarean delivery. Prim Care Clin Office Pract; 39: 145-165.

3. El-Garhy EL, Mohammed AH, Abd-ElMotaal AS and Esmail MNI (2018): Prediction of delivery mode in pregnant women using angle of progression before onset of labor. Nat Sci; 16: 1-4.

4. EL-Nassery N.S., EL-Kattan E.A., Fouad M.A. and Affifi T.M. (2013): Unengaged head in primigravidas, will it affect the chance of having a vaginal birth? Med J Cairo Univ 81(1): 221-225.

5. Khurshid N. and Sadiq F. (2012): Management of primigravida with unengaged head at term. P J M H S 6(1): 36-39. 
6. Lane T.L., Chung C.P., Yandell P.M., Kuehl T.J. and Larsen W.I. (2017): Perineal body length and perineal lacerations during delivery in primigravid patients. Proc Bayl Univ Med Cent 30 (2): 151-153.

7. Loke A.Y., Davies L. and Li S.F. (2015): Factors influencing the decision that women make on their mode of delivery: the health belief model. BMC Health Services Research; 15: 274.

8. Madaan S., Mendiratta S.L., Jain P.K. and Mittal M. (2015): Aminotic Fluid Index and its Correlation with Fetal Growth and Perinatal Outcome. J Fetal Med 2: 61-67.

9. Mahajan N., Mustafa S., Tabassum S. and Fareed P. (2016): Outcome of high fetal station in primigravida at term in labor. Int $\mathbf{J}$ Reprod Contracept Obstet Gynecol; 5(3): 873877.

10. Mahendra G. and Prameela C. (2014): Clinical study of unengaged head in primigravida at term in labor. Int $\mathbf{J}$ Rec Tren Sci Technol 10(2): 345- 349.

11. Morris R., Meller C.H., and Tamblyn J. (2014): Association and prediction of amniotic fluid measurements for adverse pregnancy outcome: systematic review and meta-analysis. Br J Obst Gynecol; 121(6): 686-699.

12. Shaikh F., Shaikh S. and Shaikh N. (2014): Outcome of primigravida with high head at term. J Pak Med Assoc; 64(9): 1012-1014.

13. Simkin P. (2010): The fetal occiput posterior position: state of the science and a new perspective. Birth 37(1): 61-71.

14. Sudhir S. and Mishra S. (2016): The outcome of labor in primigravida with term gestation and unengaged head at onset of labor. Indian J Obst Gynecol Res 3(3): 199202. 


\section{تحديد معدلات الجنين ومعدلاث الولادة الطبيعية في الحوامل

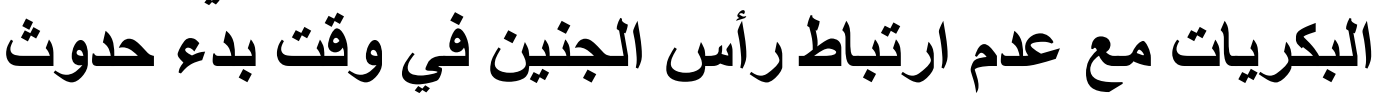

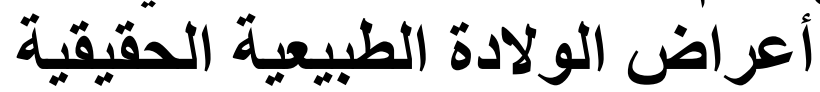 \\ السبد أحمد الاسوقي، السبد فرج، عطيه محمد}

قسم أمراض النساء والتوليد، كلية الطب، جامعة الأزهر، القاهرة

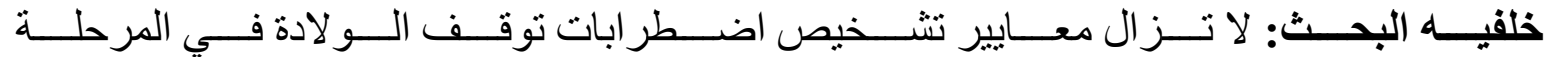

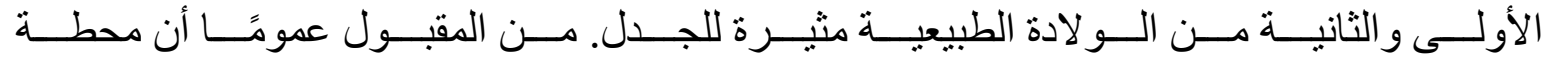

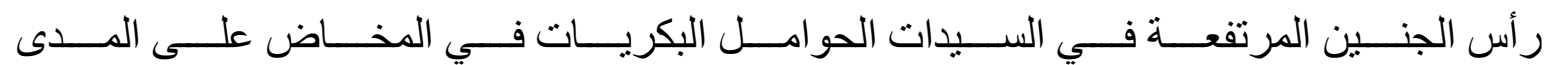

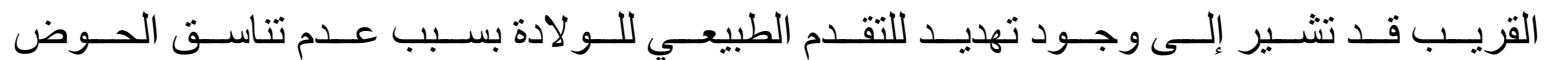
أو انسداد مرور الجنين بسبب اور ام أو المثيمة الغير طبيعية الأوضاع.

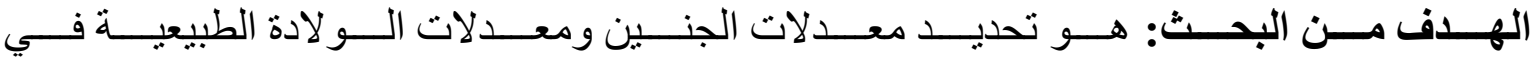

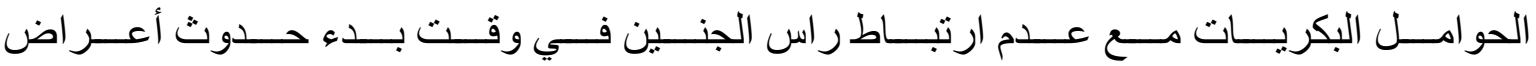

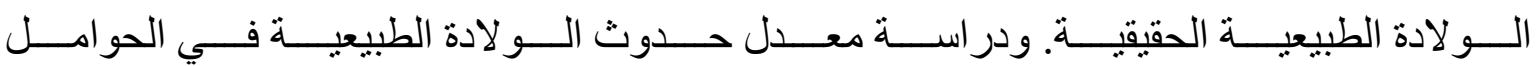

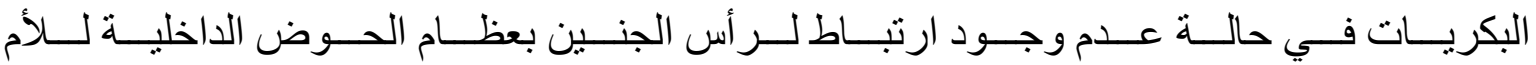
وقت بدء حدوث أعر اض الو لادة الطبيعية الحقيقية.

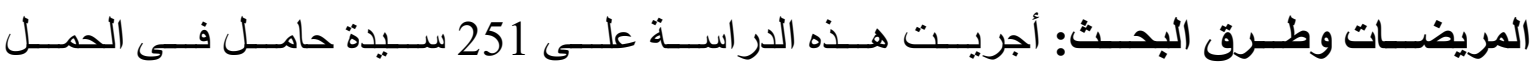

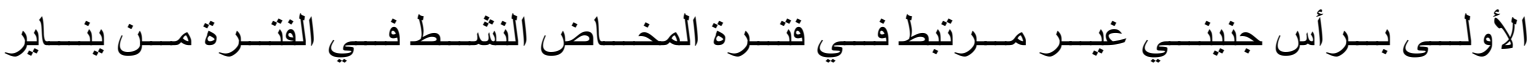

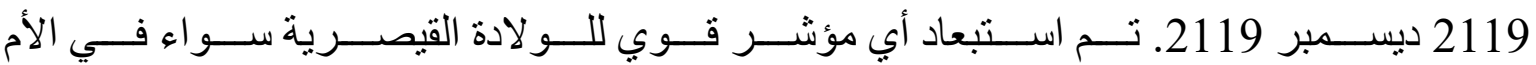

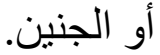

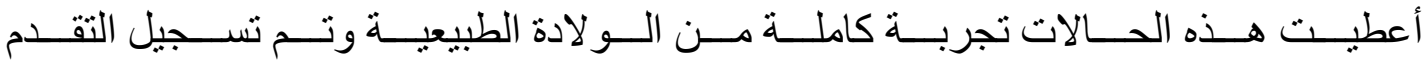

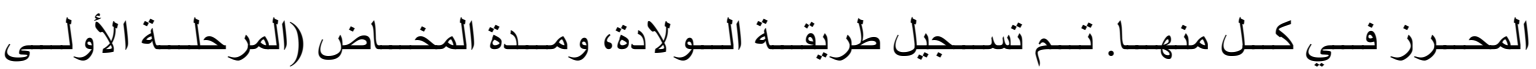

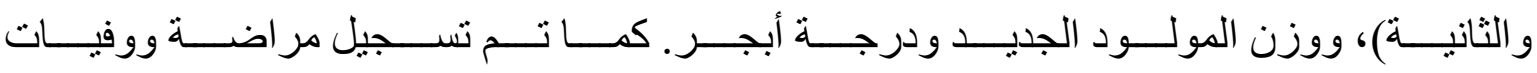

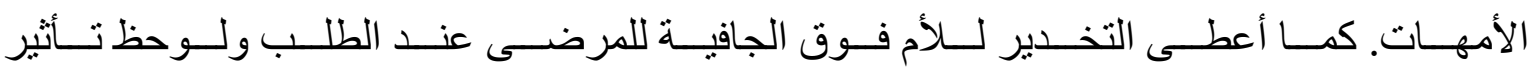

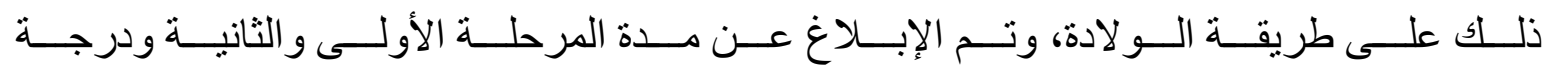




\section{EL-SAYED AHMED EL-DESOUKY et al.,}

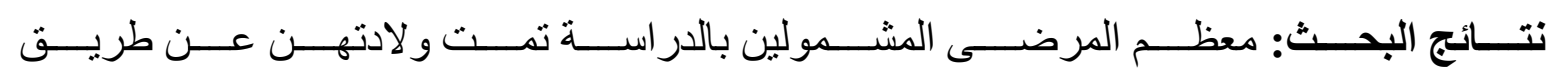

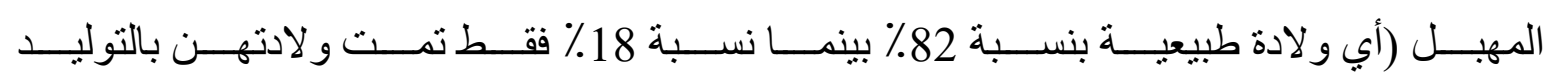

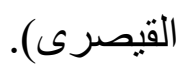

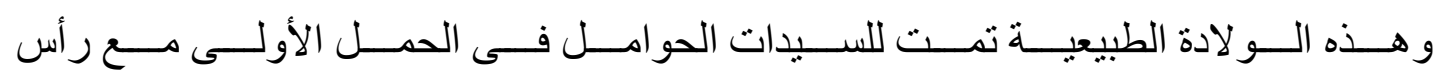

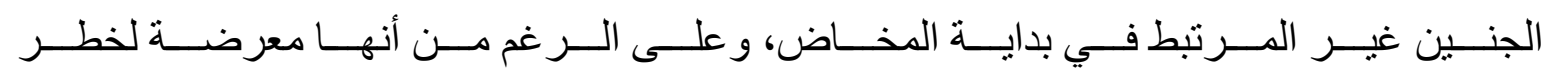

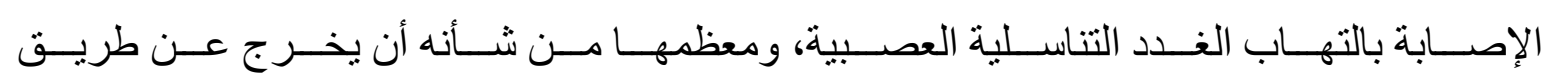

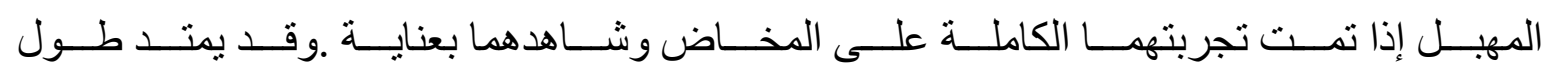

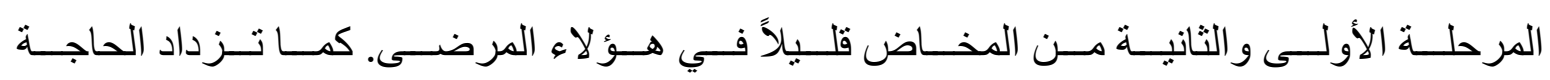
إلى زيادة الأوكسيتوسين في هؤلاء المرضى.

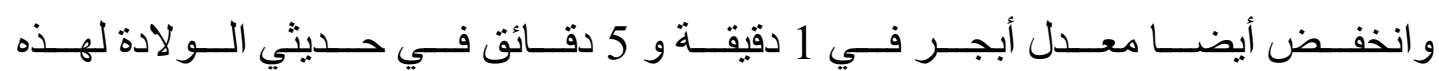
السيدات الحو امل فى الحمل الأولى. - واني.

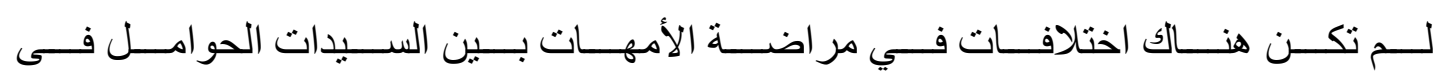

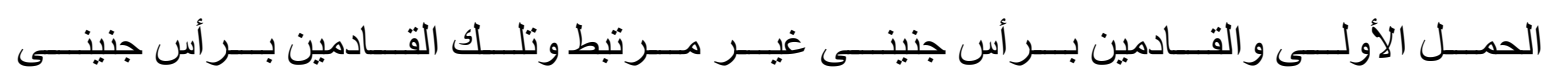
مرتبط.

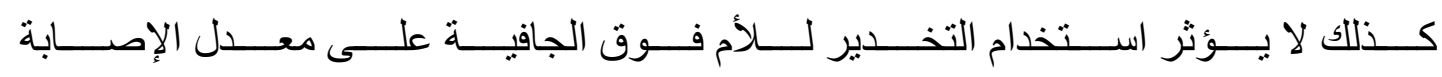

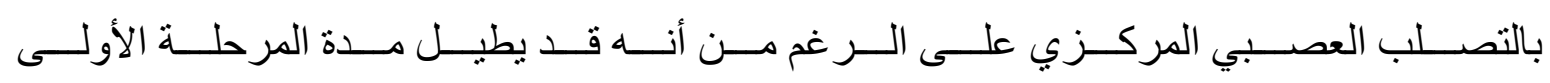

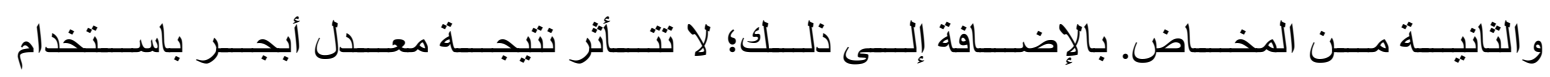
التخدير فوق الام الجافية.

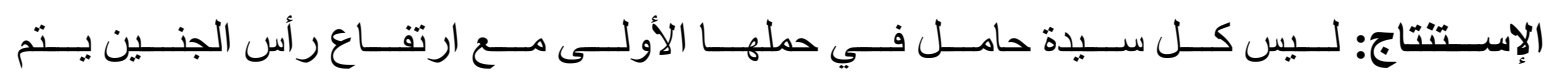

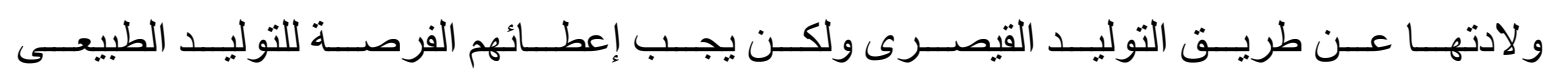

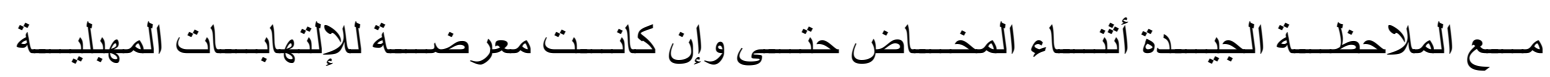
الناتجة عن الفحص المهبلى أثناء المتابعة للتوليد الطبيعى. 